\title{
Violence and Local Development in Fortaleza, Brazil: A Spatial Regression Analysis
}

\author{
Victor Hugo de Oliveira ${ }^{1}$ \\ Cleyber Nascimento de Medeiros ${ }^{2}$ \\ José Raimundo Carvalho ${ }^{3}$
}

August 17, 2017

\begin{abstract}
Fortaleza is the fifth largest city of Brazil, and has become the most violent state capital in the last years. In this paper, we investigate whether violent crime rates are associated with the local development of the city. Using an unexplored data source about georeferenced murders and deaths due to bodily injury and theft, we show that violent crime rates exhibit a positive spatial dependence across clusters of census tracts. In other words, small urban areas with high (low) violent crime rates have neighbors, on average, with similar pattern of violent crime rates. Investigating the relationship between violent crime rates and variables associated with local development, spatial regressions suggest that high violent crime rates are related with low-income neighborhood, with high spatial isolation of poor households, low access to urban infrastructure, and high prevalence of illiterate adolescents and young black males. The study also provides important evidence about spillover effects that helps to understand how the absence of local development can expose neighbors to violence.
\end{abstract}

Keywords. Violence, Local Development, Spatial Analysis, Fortaleza, Brazil.

\footnotetext{
${ }^{1}$ Instituto de Pesquisa e Estratégia Econômica do Ceará (IPECE), and Universidade de Fortaleza (UNIFOR). Address: Av. General Afonso Albuquerque Lima, S/N, Cambeba, 60822-325, Fortaleza, Ceará, Brazil. Phone: +55 85987871979 / +55 85 31013507; Fax: +55 8531013500

Corresponding author: vhosilva@gmail.com / victor.hugo@ipece.ce.gov.br.

${ }^{2}$ Instituto de Pesquisa e Estratégia Econômica do Ceará (IPECE).

Address: Av. General Afonso Albuquerque Lima, S/N, Cambeba, 60822-325, Fortaleza, Ceará, Brazil.

${ }^{3}$ Programa de Pós-Graduação em Economia, Universidade Federal do Ceará (CAEN/UFC).

Address: Avenida da Universidade 2700, Benfica, 60020-181, Fortaleza, Ceará, Brazil.
} 


\section{Introduction}

Violence is a universal scourge that tears at the fabric of communities and threatens the life, health and happiness of us all (WHO 2002). Moreover, it generates uncertainty and fear, being an important barrier to a social development (Sen 1999), inhibiting the full exercise of citizenship (Wheeler 2014), deteriorating competitiveness and business environment (Goldberg et al. 2014), and reducing investment and slowing economic growth (Skaperda et al. 2009).

In Brazil, around 50,000 lives are lost every year due to violence since $2009 .{ }^{4}$ The estimated cost with human capital losses caused by homicides reached 2.3\% of GDP in 2007. Although the overall homicide rate has remained stable since the beginning of the 1980s, the disparities at sub-national level have increased substantially since the 2000s (UNODC 2014). A remarkable case is Fortaleza, the fifth largest Brazilian city, which became the most violent Brazilian capital in 2014. Its total deaths due to violence is higher than the recorded cases in São Paulo and Rio de Janeiro, respectively the first and the second largest cities of Brazil. ${ }^{5}$

In this paper, we aim to understand the role of local development behinds the high violent crime rates in Fortaleza, Brazil. Local development is of particular importance for predicting crime behavior, once individuals may respond to economic incentives associated with criminal activities as predicted in the seminal study of Becker (1968). ${ }^{6}$ Subsequent works have also shown that the attractiveness of the criminal activity is closely related to variables that undergo significant changes during the process of economic development, such as per capita income, income distribution, urbanization and institutional development (Soares 2004).

However, economic development proxied by per capita income has an ambiguous effect on crime, whereas income inequality is positively related to crime rates (Ehrlich 1973). Theoretical and empirical studies confirmed that unequal societies are much more violent due to high criminal gains (Kelly 2000; Fanjzylber et al. 2002b; Soares 2004). Brazil is a striking example (Carvalho et al. 2005; Carvalho and Lavor 2009; Justus et al. 2015). Thus, income distribution has been accepted as a measure of the distance between gains and opportunity costs from crime (Chiu and Madden 1998; Bourguignon 1999).

The positive relationship between crimes and income inequality is also reported in sociological and criminal studies (Blau and Blau 1982; Bailey 1984; Messner et al. 2002), especially in studies based on the Theory of Anomie of Merton (1968). This theory predicts that crime is perpetrated by disadvantaged individuals who would feel a strain or extra pressure caused by the perceived wealth difference relative to the rich individuals (Kawachi et al. 1999). Such view has been found in economic studies as well (Kelly 2000). Recently, Hicks and Hicks (2014) find a positive association between crime and visible expenditure inequality using U.S. data, supporting Merton's theory. In particular, the growing gap between rich and poor reduces social cohesion, being also associated with increased firearm homicides (Kennedy et al. 1998).

\footnotetext{
${ }^{4}$ The Forum Brasileiro de Segurança Pública produces its annual report with the main statistics about public safety in Brazil. According to these reports, the total number of deaths due to murders, bodily injury and theft are the following: 44,518 (2009), 43,272 (2010), 48,084 (2011), 53,054 (2012), 51,063 (2013), 57,091 (2014), and 55,574 (2015). These statistics at state level can be found in: http://www.forumseguranca.org.br/.

5 The number of deaths caused by violence in Fortaleza was 1,989 in 2014, which means a rate per 100,000 inhabitants of 77.3. In São Paulo and Rio de Janeiro, violence caused, respectively, 1,360 and 1,305 deaths in the same year, but they exhibit much smaller violent crime rates (11.4 and 20.2) (FBSP 2015).

${ }^{6}$ In Economics, an individual's decision of engaging in criminal activities is a function of the expected costs and benefits in comparison to what could be obtained in the labor market (Becker, 1968; Stigler, 1970). Such decision making process takes into account the chance of being apprehended, costs associated with the crime execution, the expected punishment, as well as the income from legitimate activities (Freeman 1999; Fajnzylber et al. 2002a,b).
} 
Furthermore, unequal societies often devote more resources to protect the rich from victimization and, hence, crimes against high-income individuals pose greater probabilities of apprehension and punishment to offenders. In contrast, offenders may prefer to victimize the poor because of the lower risk of apprehension and punishment (Bourguignon 1999). Besides, poverty-concentrated neighborhoods are heavily populated by individuals with high risks of both offending and victimization due to high supply and demand of criminal opportunities (Cook, 1986). In Latin American cities, for instance, violence mainly affects the popular peripheries, especially shantytowns (Glebbeek and Koonings 2015). The inability of those cities to keep up with the increasing demand for public services (e.g. public safety) can lead to high levels of crime rates (Gaviria and Pagés 2002). ${ }^{7}$

In large cities of the U.S., the positive association between inequality and violent crimes is mostly driven by the effect of poverty concentration, instead of local inequality (Kang 2015). In particular, spatial isolation of disadvantaged communities would be criminogenic due to the higher prevalence of social disorganization and the lack of social control (Krivo and Peterson 1996; Xie 2010; Quillian 2012). It increases the sense of territorialism among their inhabitants and the animosity with outside groups due to the lack of social interactions which leads to increases in violent crimes (Corvalan and Vargas 2015).

Therefore, we investigate whether violent crime rates in Fortaleza is associated with local development, which is proxied by average income, income inequality and spatial isolation of poor households. It is also worthwhile to mention that our analysis uses an unexplored data source of georeferenced data about lethal crimes from 2012 to 2014. In order to perform the analysis, we adopt the spatial regression models that have been increasingly used to explain such socioeconomic phenomenon (Anselin 1988; Tita and Radil 2010). The estimates show that local development matters to predict violent crime rates in Fortaleza. We also observe that violent crime rates of urban areas are influenced by the spatial isolation of poor households and population density of the neighboring area, revealing spillover effects. Thus, our study contributes to understand how local development is associated with violent crime rates in the most violent state capital of Brazil.

\section{Data Sources}

\section{General Features of the City}

Fortaleza is the capital of the state of Ceará in the Northeast region of Brazil. Its population is about 2.45 million inhabitants with an area of $314.9 \mathrm{Km}^{2}$, according to the 2010 Demographic Census of the Instituto Brasileiro de Geografia e Estatística (IBGE). Its total GDP in 2013 was near R\$ 49.7 Billion (US\$ PPP 39.8 Billion), the $12^{\text {th }}$ largest municipal economy of the country. ${ }^{8}$ The Human Development Index is 0,754 , only the $474^{\text {th }}$ position among Brazilian municipalities in $2010 .{ }^{9}$

For the purpose of the study, we use the subdivision of metropolitan regions, called Human Development Units (HDUs), which was defined as the smallest geographical unit in the 2013 Brazilian Atlas of Human Development for the Metropolitan Regions, produced by the United Nations Development Program (UNPD) in Brazil. In particular, a Human Development Unit is a cluster of census tracts of the 2010

\footnotetext{
${ }^{7}$ For instance, Mimmi and Ecer (2010) show evidence that illegal connections and energy thefts are mostly explained as the urban slum dwellers' response to non-affordable prices of electricity in Belo Horizonte, state capital of Minas Gerais, Brazil.

${ }^{8} \mathrm{http://downloads.ibge.gov.br/}$

${ }^{9}$ http://atlasbrasil.org.br/2013/
} 
Demographic Census, which are homogeneous in terms of per capita household income. ${ }^{10}$ Fortaleza is subdivided into 247 HDUs with at least 400 domiciles each. Fig.1 presents the map of the city, and its subdivisions in HDUs.

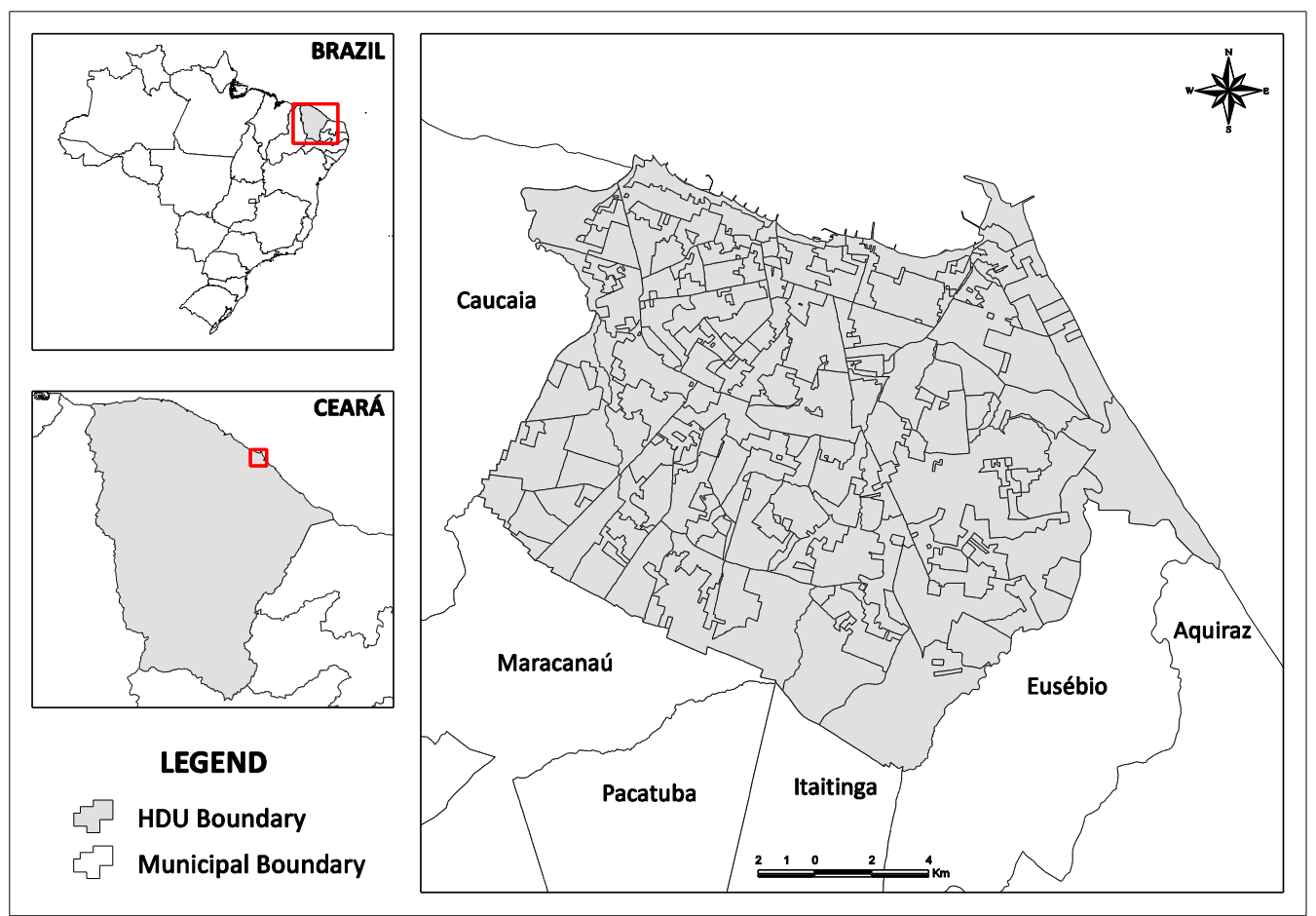

Fig.1: Fortaleza and its Human Development Units, Ceará, Brazil.

The objective is to combine the violent crime rates with socioeconomic and demographic indicators at the level of HDUs. The next subsections present the violent crime rates and the main measures of the local development adopted in the current study.

\section{Violent Crime Rates in Fortaleza}

We start the current subsection by presenting the most recent trends of the violent crimes in Fortaleza. In this study, violent crimes are related to lethal crimes which include murders, bodily injury or theft that caused victim's death. Table 1 shows that Fortaleza responds, on average, for $43.8 \%$ of all violent crimes in the State of Ceará, and for 3.0\% of all violent crimes in Brazil between 2009 and 2015. ${ }^{11}$ Violent crimes increased substantially in the period, especially in the state capital and, therefore, in the whole Ceará State. The number of occurrences doubled between 2009 and 2013, jumping from 977 to 1,993 in Fortaleza. Nonetheless, a decreasing

\footnotetext{
${ }^{10}$ The quality of data coverage of the Brazilian Demographic Census has improved substantially since the $1970 \mathrm{~s}$. One of the biggest improvements of the 2010 Brazilian Census is the incorporation of new methodologies and technologies. For instance, the use of handheld devices in the 2010 Census and Post Enumeration Survey (PES) allowed improvement of quality and timeliness in the data collection process, and facilitated automatic matching of PES to the Census. The enumeration process was conducted in urban and rural areas, except in campsites, military bases, ships, boats, indigenous areas; and institutions such as penitentiary institutions, asylums, orphanages, convents and hospitals. Coverage rates were estimated for occupied private housing units and people living there (da Silva et al. 2015).

11 This evidence corroborates the literature which argues that large cities concentrate criminal activity and violence (Glaeser and Sacerdote 1999).
} 
trend is observed in the two subsequent years, in which the total events dropped to 1,989 in 2014 and 1,651 in 2015. In terms of incidence rate, the violent crime rate per 100,000 inhabitants increased from 39 to 78.1 between 2009 and 2013, a variation of 100\%. In 2015, the rate dropped to 63.3 per 100,000 inhabitants, but it still was almost 2.5 times larger than the rate for the whole country.

Table 1: Violent crimes in Fortaleza and Ceará State from 2009 to 2015

\begin{tabular}{ccccccccc}
\hline & \multicolumn{3}{c}{ Total Violent Crimes } & \multicolumn{3}{c}{$\begin{array}{c}\text { Violent Crime Rate } \\
\text { (per 100,000 inhabitants) }\end{array}$} \\
\cline { 2 - 8 } & $\begin{array}{c}\text { Fortaleza } \\
(\mathrm{A})\end{array}$ & $\begin{array}{c}\text { Ceará } \\
(\mathrm{B})\end{array}$ & $\begin{array}{c}\text { Brazil } \\
(\mathrm{C})\end{array}$ & $\begin{array}{c}\mathrm{A} / \mathrm{B} \\
(\%)\end{array}$ & $\begin{array}{c}\mathrm{A} / \mathrm{C} \\
(\%)\end{array}$ & Fortaleza & Ceará & Brazil \\
\hline 2009 & 977 & 2,382 & 44,518 & 41.0 & 2.2 & 39.0 & 27.9 & 23.2 \\
2010 & 1,233 & 2,755 & 43,272 & 44.8 & 2.8 & 50.3 & 32.6 & 22.7 \\
2011 & 1,238 & 2,762 & 48,084 & 44.8 & 2.6 & 50.0 & 32.4 & 25.0 \\
2012 & 1,689 & 3,734 & 53,054 & 45.2 & 3.2 & 67.6 & 43.4 & 27.4 \\
2013 & 1,993 & 4,435 & 53,646 & 44.9 & 3.7 & 78.1 & 50.5 & 26.6 \\
2014 & 1,989 & 4,439 & 54,023 & 42.8 & 3.7 & 77.3 & 50.2 & 26.6 \\
2015 & 1,651 & 4,019 & 52,463 & 41.1 & 3.1 & 63.3 & 45.1 & 25.7 \\
\hline
\end{tabular}

Source: Authors' elaboration using Anuário Brasileiro de Segurança Pública $\left(8^{\text {th }}\right.$ and $10^{\text {th }}$ Edition). The rate (per 100,000 inhabitants) was computed using population estimates computed by the Brazilian Institute of Geography and Statistics. In 2010, we use population from the 2010 Demographic Census.

In order to perform our analysis, we use georeferenced data on violent crimes from 2012 to 2014, provided by the Secretaria de Segurança Pública e Defesa Social do Governo do Estado do Ceará (Secretary of Public Safety and Social Defense of the Ceará State Government), in order to generate the violent crime rates at the level of HDUs (i.e., clusters of census tracts). The State Government collects information about date and time, victim's characteristics (age and gender), type of weapon, and latitude and longitude of the crime event. Unfortunately, only year and geographic coordinates were made available to this study. The following expression shows how we compute the violent crime rate (VCR) at the level of HDUs, which is given by

$V C R_{i}=\frac{1}{3}\left(\frac{\sum_{t=2012}^{2014} V C_{i t}}{P O P_{2010}}\right) \times 100,000$

where $\mathrm{VC}_{\mathrm{it}}$ is the total violent crimes at the $\mathrm{HDU} \mathrm{i}$ in the year $\mathrm{t}=(2012,2013,2014)$, and $\mathrm{POP}_{2010}$ is the population from the 2010 Demographic Census. This procedure helps us to reduce the dispersion of the variable, once some HDUs exhibit very small population size and violent crimes are rare events in these areas. The average value of the violent crime rate across HDUs is approximately 69.4 per 100,000 inhabitants with a standard deviation equal to 54.1. In the whole Latin America, the rate of violent crimes is 70 per 100,000 inhabitants (UNPD 2013). Besides, approximately $90 \%$ of all HDUs exhibit violent crime rates above the threshold for epidemic levels of violence according to the World Health Organization (i.e. 10 per 100,000 inhabitants).

Fig. 2 presents the distribution of violent crime rates at the level of UDHs. It suggests that HDUs with large violent crime rates (colors orange and red) are near areas with similar characteristic. In the other way 
around, HDUs with lower violent crime rates (colors light-green and dark-green) are very close to HDUs with similar characteristics. It means that spatial dependence is a potential characteristic of the violent crime rates in Fortaleza. $^{12}$

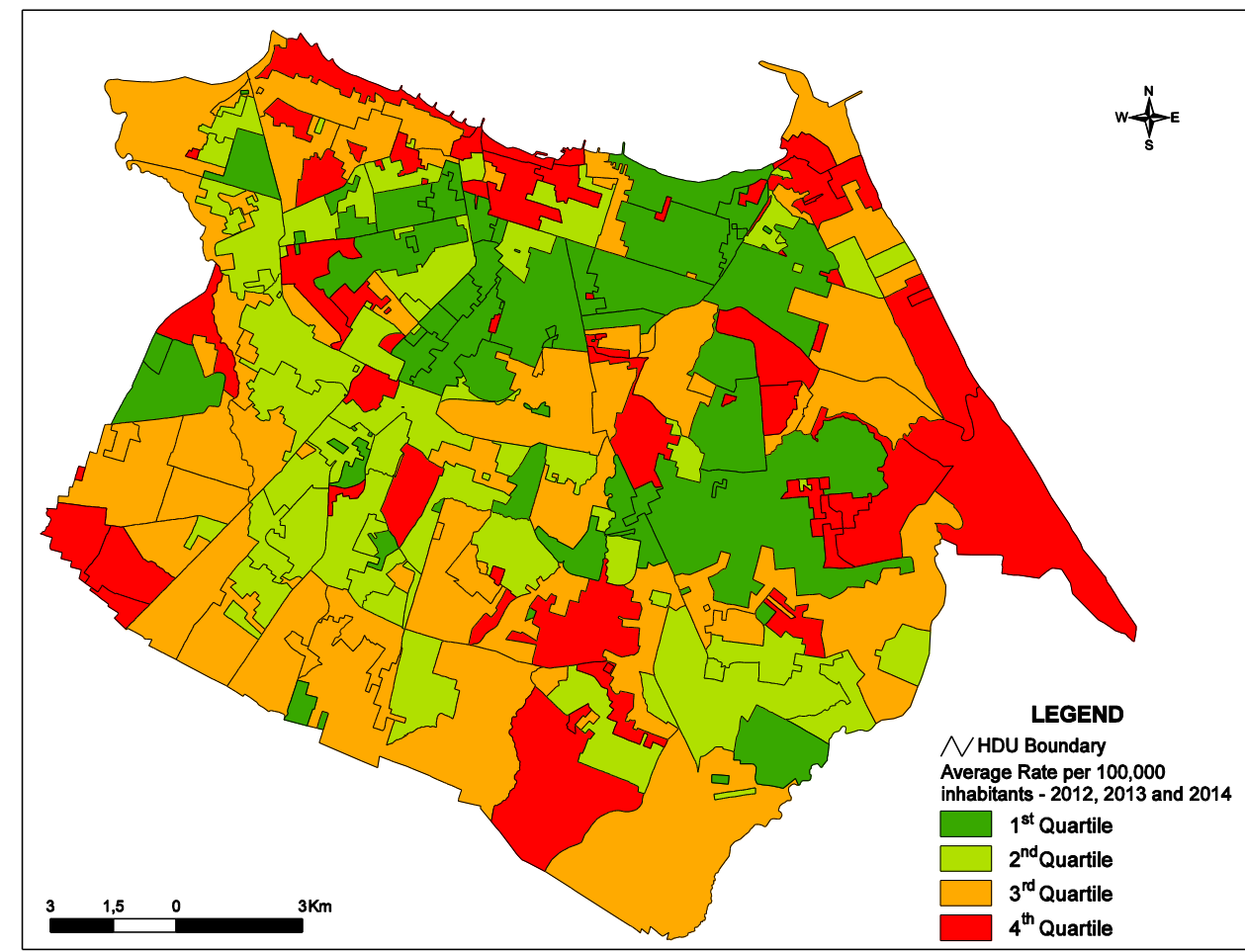

Fig. 2: Distribution of Violent Crime Rates at the level of Human Development Units

In order to verify whether violent crime rates exhibit spatial dependence, we compute the Moran I Statistic and Geary C Statistic, using both Queen and Rook contiguity matrices (i.e., spatial weight matrices). Table 2 present the estimated coefficients for spatial autocorrelation of the violent crime rates.

Table 2: Spatial Autocorrelation of the Violent Crime Rates

\begin{tabular}{lcccc}
\hline \multirow{2}{*}{ Weight matrix } & \multicolumn{2}{c}{ Moran I Statistic } & \multicolumn{2}{c}{ Geary C Statistic } \\
\cline { 2 - 5 } Rook & 0.114 & 0.117 & 0.735 & 0.735 \\
& {$[0.004]$} & {$[0.004]$} & {$[0.002]$} & {$[0.000]$} \\
Queen & 0.107 & 0.107 & 0.738 & 0.738 \\
& {$[0.006]$} & {$[0.006]$} & {$[0.002]$} & {$[0.000]$} \\
\hline Note. P-values are in brackets. Simulated p-values were obtained from 2,500 permutations.
\end{tabular}

We observe that Moran I Statistic is positive and statistically significant at the level of $1 \%$, either using standard or simulated p-values. Geary C statistic is smaller than 1 and statistically significant at the level of $1 \%$,

12 The colors comprise the following intervals of violent crime rates (VCRs): dark green includes HDUs with VCR between 0 and 35 per 100,000 inhabitants; light green includes HDUs with VCR between 36 and 58 per 100,000 inhabitants; orange includes HDUs with VCR between 59 and 98 per 100,000 inhabitants; red includes HDUs with VCR equal to 99 per 100,000 inhabitants or more. 
either using standard or simulated p-values. Thus, we conclude from Table 2 that violent crime rates exhibit a positive spatial autocorrelation in Fortaleza. In other words, HDUs with large (small) violent crime rates tend to have neighbors with large (small) violent crime rates as well.

The nature of the spatial dependence of the violent crime rates presented in Table 2 might be tentatively understood by the wave of gang fights. Based on information from Civil Police Office, local newspapers have reported an increasing number of gang fights in several neighborhoods between 2011 and 2014, especially in neighborhoods located in the periphery of the city (see Fig. $4 \mathrm{a}$ and $4 \mathrm{~b}$ in Appendix B). ${ }^{13}$

Empirical studies have shown the role played by gangs on shaping crime rates in a particular neighborhood (Tita and Ridgeway 2007) promoting the diffusion of violent crimes (Tita and Cohen 2004), specially through formation of social networks with the objective of killing members of rival gangs (Tita and Radil 2011) or in order to control local drug markets (Taniguchi et al 2011). Such social phenomenon is substantially associated with the lack of social control (Tita et al. 2005).

In addition, part of the variation in violent crime rates can be explained by the differences in the level of local development across and within HDUs. The next subsection provides details regarding the socioeconomic and demographic variables that are potential predictors of this social phenomenon in Fortaleza.

\section{Measures of Local Development}

Table 3 displays the descriptive statistics of socioeconomic and demographic indicators that are used as explanatory variables for the violent crime rates in Fortaleza. Almost all variables are available in the 2013 Brazilian Atlas of Human Development of the Metropolitan Regions at the level of HDUs, which use the 2010 Demographic Census as the primary source of information. The exception is the index of urban infrastructure, as well as the dissimilarity index of poverty, for which we use the 2010 Demographic Census at the level of census tracts to produce their values at the level of HDUs.

Table 3: Descriptive Statistics of Explanatory Variables

\begin{tabular}{llrr}
\hline Covariates & Description & Mean & Std. Dev. \\
\hline INCOME & Per capita household Income & 860.86 & 711.68 \\
GINI & Gini index & 0.46 & 0.05 \\
DPOV & Dissimilarity index of poverty & 0.13 & 0.10 \\
POPD & Population density & 165.84 & 214.78 \\
URBINF & Index of urban infrastructure & 0.71 & 0.20 \\
YBM1019 & \% self-declared blacks (“negro" or "pardo"), aged 10 to 19 & 5.56 & 1.90 \\
YBM2029 & \% self-declared blacks (“negro" or "pardo"), aged 20 to 29 & 6.09 & 1.36 \\
WOMHEAD & \% women as household head & 25.50 & 4.48 \\
ILLIT1117 & $\%$ illiterate population aged 11 to 19 & 2.20 & 1.68 \\
ILLIT18m & $\%$ illiterate population aged 18 or more & 7.07 & 4.67 \\
\hline
\end{tabular}

Source: Authors' elaboration.

\footnotetext{
${ }^{13}$ For further details, see de Castro (2014).
} 
Income is measured by the per capital household income. Although empirical studies in Economics suggest that violent crime rates are ambiguously associated with income at country level, Fig. 3 shows that such relationship may be quite different when we focus on small geographic units within a large city. In Fig. 3, it is possible to observe a negative spatial association between income and violent crime occurrences in Fortaleza. More than two-third of the violent crimes (from 2012 to 2014) took place in the low-income areas of the city (1st and 2nd quartiles).

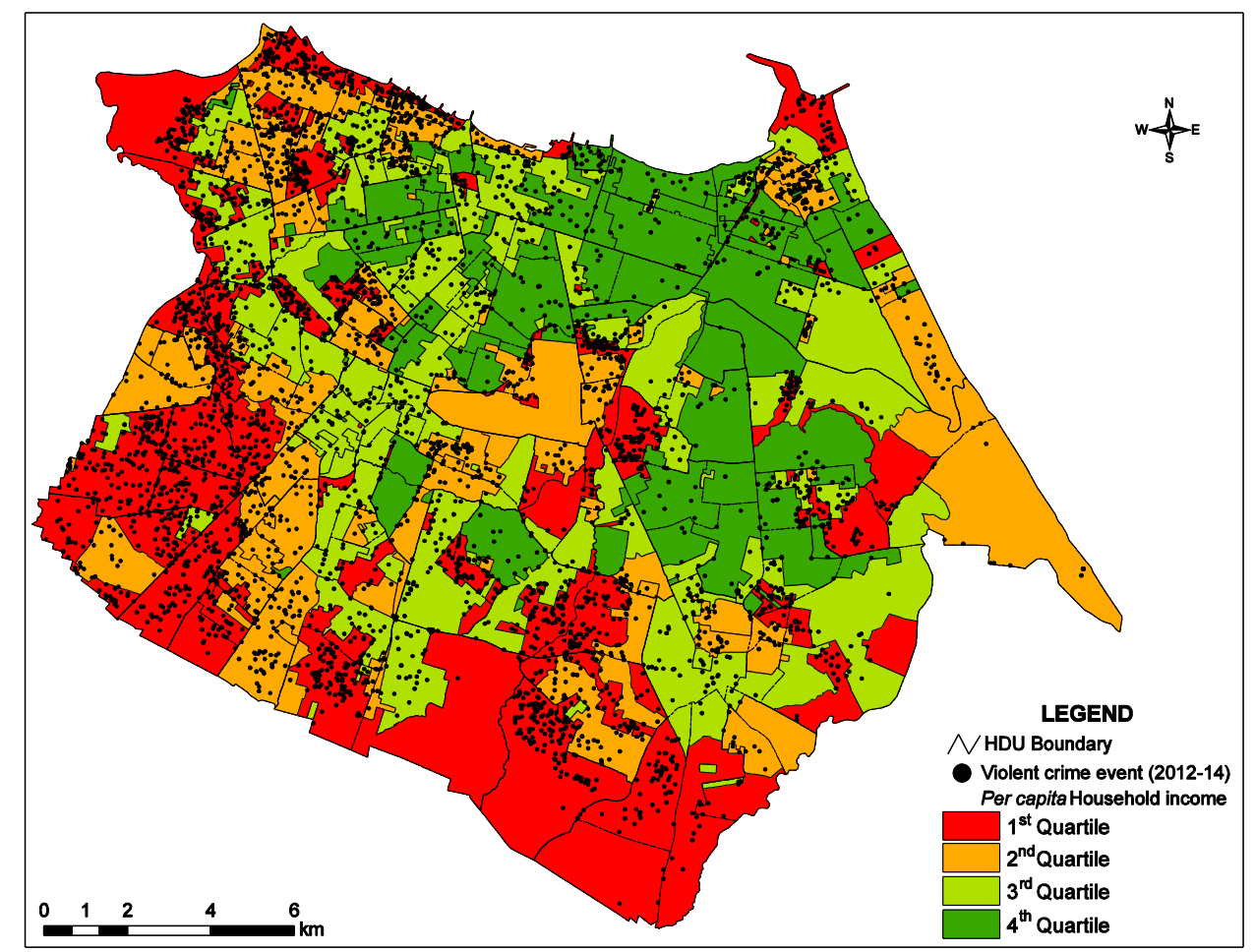

Fig. 3: Distribution of Violent Crime Events by Income Groups of HDUs

Due the fact that clusters (HDUs) were generated based on average per capita income at the level of census tracts, income inequality measured by Gini index within each cluster turns out to be smaller than it would be if another socioeconomic variable was used to generate the clusters. In this case, we would expect a smaller association between violent crime rates and within-neighborhood inequality.

Another important explanatory variable is population density. Glaeser and Sacerdote (1999) argue that large cities are very attractive for criminals, because they have access to the wealthy and find a greater density of victims in urban areas, better access to information and economies of scale (e.g., stolen goods are ease to be resold, like guns). However, Jacobs (1961) suggests that population density within urban environment (e.g. at level of census tracts) would negatively predict violent crime in the urban areas. Intuitively, crowded streets inhibit criminal behavior because it increases the risk of apprehension. Therefore, we test which of these two effects is prevalent in Fortaleza.

We also include a proxy variable for the access to urban infrastructure. This variable was generated by principal components approach, and measures the access of the population to paved streets, street light, sidewalk, curbs, culverts and afforested streets (see Appendix A). The set of variables used to construct the index can be 
accessed in the 2010 Demographic Census at the level of census tract. ${ }^{14}$ The first step is the aggregation of each variable at the level of HDUs, and the calculation of proportions once we know the total population of each HDU. The second step is to compute the index using principal components, and get its standardized values between 0 and 1. A HDU with score close to 1 means a high access to urban infrastructure, and a score close to 0 is interpreted as very low access to urban infrastructure.

In addition, homicide victims are most likely to be young, male, black, and with few years of education in Brazil (Murray et al. 2013). Particularly, the characteristic of "race" is the most controversial demographic correlate of crime. Whereas part of the literature advocates toward the predominance of the subculture of violence among African American, the most recent literature has explained the high violent crime rates among blacks as a source of socioeconomic differences and community context (South and Messner 2000). Since the current study aims to understand the socioeconomic and demographic forces behind the violent crime rates in Fortaleza, it is important to take into account demographic groups that are highly vulnerable to violent crimes. Thus, we include the proportion of population self-declared black (i.e., "negro" or "pardo") aged 10-19, and 2029 , in the vector of explanatory variables. Moreover, we add other socio-demographic variables that are also important to understand the shape of violent crimes in Fortaleza, such as the illiterate population (aged 11-19, and aged 18 or more). We add the proportion of women as household head as a proxy for family structure, which has been used as a measure of social disorganization in studies about violent crimes (Sampson 1986).

\section{Spatial Isolation of Poor Households}

An important hypothesis to be tested is whether violent crimes are more prevalent in areas where poor households are spatially isolated from non-poor households. ${ }^{15}$ Spatial isolation of disadvantaged communities would be particularly criminogenic due to the greater prevalence of social disorganization and the lack of social control (Krivo and Peterson 1996; Xie 2010; Quillian 2012). Moreover, residential segregation of poor individuals may lead them to experience low access to public goods (e.g. schools and health care centers) and lack of social interactions with other groups, and face a spatial mismatch between where they live and where jobs are located (Kain 1968; Cutler and Glaeser 1997).

Using data from the 2010 Demographic Census at the level of census tracts (IBGE 2011), we compute the residential segregation of poor households ${ }^{16}$ for each HDU based on the dissimilarity index (Massey and Denton 1988; Cutler and Glaeser 1997; Kang 2015) that is given by the following expression:

$\operatorname{DPOV}_{j}=\frac{1}{2} \sum_{i}\left|\frac{\operatorname{POOR}_{i j}}{\text { POOR }_{j}}-\frac{\operatorname{nonPOOR}_{i j}}{\text { nOnPOOR }_{j}}\right|$

where $P O O R_{i j}$ is the is the number of poor households in the census tract $i$ of a $\operatorname{HDU} j$, and $P O O R_{j}$ is the total

\footnotetext{
${ }^{14}$ Census data on socioeconomic/demographic characteristics and urban infrastructure at the level of census tract can be accessed in the following link: http://downloads.ibge.gov.br/downloads_estatisticas.htm.

${ }^{15}$ Spatial isolation, or residential segregation, is the degree of which two or more groups live separately from one another, in different parts of urban environment (Massey and Denton 1988). Groups themselves may be defined on the basis of any socially meaningful trait (e.g. race, ethnicity, income, education, or age) and segregation may occur at a variety of geographic levels (e.g. state, county, municipality, neighborhood, or block) (Massey et al. 2009).

${ }^{16}$ A poor household is any particular domicile without monthly income or with per capita monthly income smaller than 1/2 nominal minimum wage in 2010 (minimum wage in 2010 reached R $\$ 510$, or US\$ PPP 318,00 ).
} 
number of poor households of the HDU $j$. The term nonPOOR $i j$ is the total non-poor households in the census tract $i$ of the HDU $j$, and nonPOOR $R_{j}$ is the total non-poor households in the HDU $j$. The index varies from 0 to 1 , for which values close to 1 means that poor households are isolated from non-poor households in the HDU $j .{ }^{17}$ Back to Table 3, the average level of economic segregation is 0.13 with standard deviation of 0.1 .

\section{Empirical Strategy}

The empirical strategy is based on the estimation of spatial regression models, once Table 2 suggests that the violent crime rates are spatially autocorrelated. Expressions (3) and (4) provide a general formulation of the spatial regression model (LeSage and Pace 2009; Elhorst 2014), which is given by

$Y=\alpha+\rho W Y+X \beta+\theta W X+u$

$u=\lambda W u+\varepsilon$

where $\mathrm{Y}$ is a matrix $247 \times 1$, regarding violent crime rates for 247 HDUs. Matrix $\mathrm{X}$ has order $247 \times \mathrm{k}$, corresponding to $k$ explanatory variables. Matrix W is the spatial weight matrix (Queen or Rook) with order $247 \times 247$. The vector of the parameters of interest is $\beta$ with order $\mathrm{k} \times 1$. Besides, spatial parameters are $\rho$ and $\lambda$. Matrix WX has order $247 \times \mathrm{k}$, and $\theta$ captures spatial lag effects from explanatory variables. In the equation (4), the random error, $\varepsilon$, is assumed to be normally distributed with zero mean and finite variance.

Although we can access several spatial models from expressions (3) and (4), Table 2 suggests that spatial models that do not account for spatial dependence of the dependent variable may produce biased estimations. Thus, we focus our attention on the Spatial Lag Model (SAR), Spatial Autocorrelation Mode (SAC), and Spatial Durbin Model (SDM). According to LeSage and Pace (2009), if the Spatial Lag Model (SAR) is the true data generating process, SDM and SAC produce unbiased estimates with measures of coefficient dispersion being correct. Nonetheless, if the true data generating process is the SDM model, SAR and SAC will suffer from omitted variable bias. In case that SAC is the true specification, estimates from SAR and SDM will be unbiased estimates. However, incorrect inference, regarding the standard errors of the estimates, is likely to arise from SAR model when ignoring spatial dependence in the disturbances. On the other hand, the SDM model does not ignore spatial dependence in the disturbances, once it provides a different type of specification for error dependence with the inclusion of spatial lag in the explanatory variables.

Therefore, the SDM is viewed as the departure model because it produces unbiased estimates, and helps to prevent omitted variable bias (LeSage and Pace 2009). In order to obtain the appropriate model, we perform specifications tests for hypotheses $\mathrm{H}_{0}: \theta=0$ and $\mathrm{H}_{0}: \theta+\rho \beta$. The first hypothesis examines whether SDM can be simplified to SAR, and the second hypothesis whether SDM can be simplified to the SEM (Elhorst 2014). We also provides LR and Wald test to compare SDM and SAC models.

\footnotetext{
${ }^{17}$ Poor households are said to be segregated if they are unevenly distributed over the census tract of a HDU. Isolation is minimized when all census tracts have the same relative number of poor and non-poor households as the HDU as a whole. Conversely, it is maximized when poor households and non-poor do not share the same census tract of residence. Kang (2015) used the dissimilarity index of poverty as a proxy for economic segregation.
} 


\section{Results}

\section{Spatial Dependence and Model Comparison}

Before presenting the estimates from spatial models, we have to verify whether residuals from the Ordinary Least Square (OLS) exhibit spatial dependence or not. Table 4 displays Moran I Statistic and Geary C Statistic, and confirms the presence of spatial dependence in residuals using both methods. It means that the OLS estimates are biased due to the unobservable spatial dependence.

Table 4: Spatial Autocorrelation Coefficients for Residuals from OLS

\begin{tabular}{|c|c|c|c|c|}
\hline \multirow[b]{2}{*}{ Weight matrix } & \multicolumn{2}{|c|}{ Moran I Statistic } & \multicolumn{2}{|c|}{ Geary C Statistic } \\
\hline & Standard & Permutations & Standard & Permutations \\
\hline \multirow[t]{2}{*}{ Rook } & 0.155 & 0.155 & 0.647 & 0.647 \\
\hline & {$[0.000]$} & {$[0.000]$} & {$[0.000]$} & [0.000] \\
\hline \multirow[t]{2}{*}{ Queen } & 0.151 & 0.151 & 0.650 & 0.650 \\
\hline & {$[0.000]$} & {$[0.002]$} & {$[0.000]$} & {$[0.000]$} \\
\hline
\end{tabular}

Note. P-values are in brackets. Simulated p-values were obtained from 2,500 permutations.

Table 5 displays Likelihood Ratio Test (LR test) and Wald test, comparing the SDM with restricted specifications (SAR, SEM, and SAC). Either using Queen or Rook weight matrix, both tests suggest that the SDM model is the best specification.

Table 5: Comparing the Spatial Durbin Model with Restricted Specifications

\begin{tabular}{lccc}
\hline & SAR & SEM & SAC \\
\hline Queen & $H_{0}: \theta=0$ & $H_{0}: \theta+\rho \beta=0$ & \\
LR test & 22.080 & & 15.508 \\
& {$[0.015]$} & 15.584 & {$[0.078]$} \\
Wald test & 23.651 & {$[0.112]$} & 23.651 \\
& {$[0.009]$} & 39.821 & {$[0.005]$} \\
\hline Rook & & {$[0.000]$} & \\
LR test & 23.937 & & 16.413 \\
& {$[0.008]$} & 16.417 & {$[0.059]$} \\
Wald test & 25.883 & {$[0.088]$} & 25.883 \\
& {$[0.004]$} & 47.477 & {$[0.002]$} \\
\hline
\end{tabular}

Note. P-values are in brackets.

Table 6 comprises estimates from OLS and SDM. The estimates of the spatial coefficient, $\hat{\rho}$, is about 0.33 using Queen format, and 0.36 using Rook format of the weight matrix. Those coefficients support the previous evidence about the positive spatial autocorrelation in violent crime rates in Fortaleza. Moreover, the results from SDM suggest that important associations from spatially lagged explanatory variables cannot be neglected, especially related to the dissimilarity index of poverty (DPOV) and population density (POPD).

However, the estimates for the SDM model presented in Table 6 cannot be interpreted as partial 
derivatives in the typical regression model fashion. In order to access the correct signs and magnitudes of the coefficients, we have to estimate the direct, indirect and total impacts (LeSage and Pace 2009). In the next subsection, we use the estimations from the SDM with Rook weight matrix for interpretation, once it provides the smaller AIC and the larger Log-likelihood than the SDM model with Queen weight matrix.

Table 6: Results from OLS and Spatial Durbin Model

\begin{tabular}{|c|c|c|c|c|c|c|c|c|c|c|}
\hline \multirow{4}{*}{$\begin{array}{l}\text { Covariates } \\
\ln (\mathrm{INCOME})\end{array}$} & \multirow[b]{2}{*}{ OLS } & & \multicolumn{4}{|c|}{ SDM - Queen Weight Matrix } & \multicolumn{4}{|c|}{ SDM - Rook Weight Matrix } \\
\hline & & & \multirow{2}{*}{$\begin{array}{c}\widehat{\widehat{\boldsymbol{\beta}}} \\
-0.584\end{array}$} & \multicolumn{3}{|c|}{$\widehat{\boldsymbol{\theta}}$} & \multirow{2}{*}{$\begin{array}{c}\widehat{\widehat{\boldsymbol{\beta}}} \\
-0.556\end{array}$} & \multicolumn{3}{|c|}{$\widehat{\boldsymbol{\theta}}$} \\
\hline & -0.243 & & & $* *$ & 0.390 & & & $* *$ & 0.345 & \\
\hline & $(0.261)$ & & $(0.281)$ & & $(0.469)$ & & $(0.279)$ & & $(0.457)$ & \\
\hline \multirow[t]{2}{*}{ GINI } & 1.221 & & 2.514 & & 0.607 & & 2.492 & & -0.555 & \\
\hline & $(2.031)$ & & $(1.909)$ & & $(3.321)$ & & $(1.887)$ & & $(3.246)$ & \\
\hline \multirow[t]{2}{*}{ DPOV } & 1.908 & $* *$ & 1.433 & $*$ & 3.696 & $*$ & 1.413 & $*$ & 3.973 & $* *$ \\
\hline & $(0.796)$ & & $(0.758)$ & & $(2.047)$ & & $(0.752)$ & & $(2.001)$ & \\
\hline \multirow[t]{2}{*}{ URBINF } & -0.510 & & -0.867 & $* *$ & 1.333 & & -0.948 & $* *$ & 1.420 & \\
\hline & $(0.467)$ & & $(0.450)$ & & (1.194) & & $(0.446)$ & & $(1.121)$ & \\
\hline \multirow[t]{2}{*}{ POPD } & -0.002 & $* * *$ & -0.002 & $* * *$ & 0.004 & $* * *$ & -0.002 & $* * *$ & 0.004 & $* * *$ \\
\hline & $(0.000)$ & & $(0.000)$ & & $(0.001)$ & & $(0.000)$ & & $(0.001)$ & \\
\hline \multirow[t]{2}{*}{ YBM1019 } & 0.235 & $* * *$ & 0.222 & $* * *$ & -0.015 & & 0.220 & $* * *$ & -0.043 & \\
\hline & $(0.082)$ & & $(0.079)$ & & $(0.165)$ & & $(0.078)$ & & $(0.165)$ & \\
\hline \multirow[t]{2}{*}{ YBM2029 } & -0.055 & & -0.120 & & 0.248 & & -0.113 & & 0.238 & \\
\hline & $(0.076)$ & & $(0.074)$ & & $(0.193)$ & & $(0.073)$ & & $(0.186)$ & \\
\hline \multirow[t]{2}{*}{ WOMHEAD } & -0.009 & & -0.014 & & 0.033 & & -0.014 & & 0.028 & \\
\hline & $(0.017)$ & & $(0.016)$ & & $(0.041)$ & & $(0.016)$ & & $(0.041)$ & \\
\hline \multirow[t]{2}{*}{ ILLIT1019 } & 0.117 & $* *$ & 0.116 & $* *$ & -0.018 & & 0.112 & $* *$ & -0.030 & \\
\hline & $(0.059)$ & & $(0.056)$ & & $(0.151)$ & & $(0.056)$ & & $(0.146)$ & \\
\hline \multirow[t]{2}{*}{ ILLIT18m } & -0.030 & & -0.048 & & 0.073 & & -0.046 & & 0.078 & \\
\hline & $(0.032)$ & & $(0.032)$ & & $(0.072)$ & & $(0.032)$ & & $(0.071)$ & \\
\hline \multirow[t]{2}{*}{$\hat{\rho}$} & & & & & 0.326 & $* * *$ & & & 0.362 & $* * *$ \\
\hline & & & & & $(0.079)$ & & & & $(0.076)$ & \\
\hline \multicolumn{11}{|c|}{ Residual Autocorrelation } \\
\hline LM test & & & & & 0.014 & & & & 0.269 & \\
\hline AIC & & & & & 770.89 & & & & 769.68 & \\
\hline Log-likelihood & & & & & -359.49 & & & & -357.80 & \\
\hline Observations & 247 & & & & 247 & & & & 247 & \\
\hline
\end{tabular}

Note. Estimates from restricted models (SAR, SEM and SAC) are available upon request.

$* * *$ p-value $<0.01, * *$ p-value $<0.05, *$ p-value $<0.1$

\section{Direct, Indirect and Total Effects}

Table 7 displays the estimated direct, indirect and total effects from the Spatial Durbin Model (SDM). The estimates of SDM specification in Table 6 are informative about the direct and indirect effects, but their 
computation is much more complex as shown by LeSage and Pace (2009) and Elhorst (2014). Whereas the direct effect of the explanatory variable $X_{k}$ is composed by diagonal elements of the matrix $(I-\rho W)^{-1}\left(\beta_{k}+W \theta_{k}\right)$, the indirect effect is composed by off-diagonal elements. It is also important to highlight that the direct effect arises as a result of feedback effects, i.e., impacts passing through neighboring units and back to the unit itself. The total effects are impacts from the unity on itself and on neighboring units. The indirect impacts are the difference between total and direct effects.

Results in Table 7 reveal that violent crime rate is negatively associated with income, -0.55 , corroborating the previous evidence in Fig. 3. An increase of about $10 \%$ in the per capita household income is directly associated with a decrease of $5.5 \%$ in the average violent crime rate. Indirect and total effects are statistically insignificant. Spatial analyses for Recife, another large Northeastern capital in Brazil, reveal similar magnitude of the association between homicide rate and income. Menezes et al. (2013) using data at district level find an estimate of -0.609 and -0.468 , respectively for SAR and SEM specifications. Pereira et al (2015) using data at census tract level find a coefficient of -0.695 using the SEM specification.

Table 7: Total, Direct and Indirect Impacts from SDM Model

\begin{tabular}{|c|c|c|c|c|c|c|}
\hline Covariates & Direct & & Indirect & & Total & \\
\hline \multirow[t]{2}{*}{$\ln (\mathrm{INCOME})$} & -0.545 & $* *$ & 0.215 & & -0.330 & \\
\hline & {$[-1.956]$} & & {$[0.303]$} & & {$[-0.430]$} & \\
\hline \multirow[t]{2}{*}{ GINI } & 2.518 & & 0.520 & & 3.038 & \\
\hline & [1.284] & & [0.129] & & {$[0.503]$} & \\
\hline \multirow[t]{2}{*}{ DPOV } & 1.74 & $* *$ & 6.699 & $* *$ & 8.444 & $* *$ \\
\hline & [2.192] & & [2.112] & & {$[2.360]$} & \\
\hline \multirow[t]{2}{*}{ URBINF } & -0.868 & $* *$ & 1.609 & & 0.741 & \\
\hline & [-1.958] & & {$[0.936]$} & & {$[0.390]$} & \\
\hline \multirow[t]{2}{*}{ POPD } & -0.002 & $* * *$ & 0.005 & $* * *$ & 0.003 & \\
\hline & {$[-5.239]$} & & {$[2.675]$} & & [1.603] & \\
\hline \multirow[t]{2}{*}{ YBM1019 } & 0.223 & $* * *$ & 0.054 & & 0.277 & \\
\hline & [2.696] & & {$[0.222]$} & & [0.961] & \\
\hline \multirow[t]{2}{*}{ YBM2029 } & -0.098 & & 0.294 & & 0.195 & \\
\hline & {$[-1.325]$} & & [1.060] & & {$[0.662]$} & \\
\hline \multirow[t]{2}{*}{ WOMHEAD } & -0.012 & & 0.034 & & 0.022 & \\
\hline & {$[-0.793]$} & & {$[0.553]$} & & [0.319] & \\
\hline \multirow[t]{2}{*}{ ILLIT1117 } & $0.113^{*}$ & $*$ & 0.016 & & 0.128 & \\
\hline & [1.944] & & {$[0.050]$} & & {$[0.510]$} & \\
\hline \multirow[t]{2}{*}{ ILLIT18m } & -0.041 & & 0.092 & & 0.051 & \\
\hline & {$[-1.238]$} & & [0.849] & & [0.404] & \\
\hline
\end{tabular}

Note. Asymptotic standard errors are obtained from 2,500 draws based on Markov Chain Monte Carlo simulation. Simulated z-values are in brackets.

$* * *$ p-value $<0.01, * *$ p-value $<0.05, *$ p-value $<0.1$.

Regarding Gini index, we observe a positive and insignificant association with the violent crime rate. 
Such result is not a surprise, once an UDH is a composition of census tracts with homogeneous per capita household income, which reduces income dispersion within clusters. ${ }^{18}$

Despite the fact that the violent crime rate is not sensitive to income inequality within urban areas of Fortaleza, it is positively associated with residential segregation of poor households within HDUs. Direct effects show that a variation of 0.1 scores in the dissimilarity index is associated with a positive variation of $1.4 \%$ in the violent crime rate of the HDUs. This result corroborates Kang (2015), who suggests that economic segregation is criminogenic. The author finds a positive effect of the dissimilarity index of poverty on homicide rate of the U.S. counties, with estimates varying from 1.74 to 2.6. Interestingly, spatial lagged dissimilarity index provides a much larger effect from neighborhoods in which a variation of 0.1 scores is associated with an increase of almost $6.7 \%$ in the violent crime rate of the HDUs. Total effect of a variation of 0.1 scores in the residential segregation index increases the violent crime rate in $8.4 \%$. Therefore, urban violence may not only be influenced by the spatial isolation of poor households within the HDU, but also by the spatial isolation of poor households in the neighboring area.

Another important result in Table 7 is related to urban infrastructure. We find that the violent crime rate is directly affected by the access to urban infrastructure. If the index increases in 0.1 scores, the rate of lethal crimes decreases in $0.87 \%$. This result is in line with Gaviria and Pagés (2002), who argue that the inability of the local government in attending the increasing demand for public goods and services is an important factor that leads to high crime rates in large Latin American cities.

In addition, we find that population density exhibits a negative direct effect on violent crime rate of a HDU. On average, a variation of 100 residents per hectare is associated with a drop of $0.2 \%$ in the violent crime rate. This negative association corroborates Jacobs (1961). On the other hand, an increase of population density in the neighboring area has a positive indirect effect on the violent crime rate of the HDU, suggesting that increasing the risk of apprehension due to high population density diverts crimes to neighborhoods. ${ }^{19}$ Which effect is dominant depends on the magnitude of the coefficients. Although the total effect is positive, it is not statistically significant.

Violent crime rates are directly and positively associated with the proportion of young black males aged 11 to 19 in a HDU. An increase of 10 percentage points in the prevalence of young individuals of the HDU is associated with an increase of about $2.2 \%$ in the violent crime rate. Such result corroborates predictions of Murray et al. (2013), who suggest that homicide rates in Brazil increase with more young (black) men in the population. The indirect effect is positive, but not significant. We do not find significant estimates for the proportion of young black males aged 20 to 29.

In addition, the rate of violent crimes is directly and positively affected by the prevalence of illiterate adolescents. A positive variation of $10 \%$ in the prevalence of illiteracy among adolescents raises the violent crime rate in $1.1 \%$. However, this estimate is significant only at $10 \%$. We also include the prevalence of illiteracy for population aged 18 or more, but the variable does not exhibit significant direct and/or indirect effect. Finally, the proportion of women who are the reference person of the household does not exhibit any significant effect on violent crime rates.

\footnotetext{
${ }^{18}$ Menezes et al. (2013), on the other hand, estimate spatial regressions at level of urban districts of Recife, Pernambuco, and find a positive and significant association between homicide rate and Gini index.

${ }^{19}$ For instance, Helsley and Strange (1999) find that gated communities increases the opportunity cost of crime in the locality, but it may divert crimes to neighboring areas.
} 


\section{Conclusion}

The current study analyzed whether violent crime rates are associated with local economic development in Fortaleza, Brazil. Using an unexplored data source about georeferenced murders and deaths due to theft and bodily injury, we observe that the violent crimes exhibit a positive spatial dependence, in which areas with high incidence of murders are surrounded by areas with similar pattern of violence.

Regression models incorporating the spatial dependence show that populations in low-income areas of the city are more exposed to violence than populations in rich areas, albeit the literature has shown mixed results using data about large geographical units (i.e., municipalities, states and countries). Despite income inequality does not present predictive power, we find that spatial isolation of poor households increases local violent crime rates not only within the HDU (direct effect), but also in the neighboring area (indirect effect). High violent crime rates in segregated communities could prevail not only due to the low probability of apprehension and punishment (Bourguignon 1999; Kang 2015), but also due to high social disorganization and lack of social control (Krivo and Peterson 1996; Xie 2010; Quillian 2012).

In addition, low access of the population to urban infrastructure (such as paved streets, sidewalks, street lighting, etc.) is associated with the rate of violent crimes, suggesting that the absence of public policies to provide public goods and services to the population may expose individuals to violence (Gaviria and Pagés 2002). Moreover, population density appears to inhibit criminality within the HDU as suggested by Jacobs (1961), but increases violence in neighboring areas probably due to the diversion effect. We also find evidence that areas with high proportion of young black males and with elevated prevalence of illiterate adolescents are more likely to be exposed to violence, corroborating the general patterns of violent crime statistics for Brazil (Murray et al 2013).

It is also worth noting that our study also contributes to the scarce literature that has been dedicated to analyze the social phenomenon of crime within large Brazilian cities. For instance, some studies have examined the determinants of homicides (Menezes et al. 2013; Pereira et al. 2015), property crimes (Faria et al. 2013) and the association with fear of crime (Alkimim et al. 2013) at neighborhood level. The spatial distribution (concentration and similarity) of the urban crimes at census tract and street level has also been an object of investigation (de Melo et al. 2015).

Nonetheless, a limitation of our analysis is the fact that it is based on a cross-section data, which does not allow us to rule out other potential sources of omitted variable bias, such as the allocation of police forces in the city. On the other hand, the study provides evidence of important relationships that can be useful for improve the decisions of policy makers. For instance, improving local development with the reduction of socioeconomic inequalities across urban areas and increasing the integration of the most disadvantaged communities within urban areas arise as potential public policies that can contribute to reduce the violent crimes in the most violent state capital of Brazil.

Acknowledgments The authors would like to thank the anonymous reviewers for their comments and suggestions that helped to improve the quality of the manuscript. 
Appendix A The Urban Infrastructure Index

The urbanization index is generated by the Principal Components Approach (PCA). We include in the vector of variables: \% of domiciles in unpaved streets $(\mathrm{C} 1)$, \% of domiciles in streets without trees $(\mathrm{C} 2)$, \% of domiciles without access to street light (C3), \% of domiciles without sidewalk (C4), \% of domiciles in streets without curbs (C5), and \% of domiciles in streets without culverts (C6).

Table 8 shows the eigenvalues and eigenvectors obtained from PCA. We use the component with the largest eigenvalue to create the index which has an average of zero, varying from -2.5 to 6.19 . Large values mean low access to urban infrastructure. We transform the index using the following expression:

$$
U R B I N F_{i}=\frac{X_{M A X}-X_{i}}{X_{M A X}-X_{M I N}}
$$

where $X_{i}$ is the value of the index for neighborhood $i$, whereas $X_{M A X}$ and $X_{M I N}$ are the maximum and minimum values of the series. After performing the transformation, we find a new index varying from 0 to 1 . Notice that values near to 0 means low access to urban infrastructure and values near to 1 means high access to urban infrastructure.

The last column of Table 8 shows the correlation between the corresponding variable and the transformed index (URBINF). The coefficients show that the index is highly correlated to the proportion of domiciles without access to paved streets and sidewalk. The transformed index is less correlated to the proportion of domiciles without access to culverts.

Table 8: Contribution of the Variables to the Principal Components and Correlations with URBINF

\begin{tabular}{lccccccc} 
& \multicolumn{5}{c}{ Principal Components (Eigenvectors) } & \multirow{2}{*}{$\begin{array}{c}\text { Correlation } \\
\text { with URBINF }\end{array}$} \\
\cline { 2 - 6 } & PC1 & PC2 & PC3 & PC4 & PC5 & PC6 & -0.808 \\
C1 & 0.480 & -0.069 & 0.036 & 0.179 & -0.773 & 0.366 & -0.672 \\
C3 & 0.400 & 0.244 & 0.140 & -0.853 & 0.106 & 0.150 & -0.547 \\
C4 & 0.325 & -0.331 & 0.787 & 0.232 & 0.333 & 0.024 & -0.875 \\
C5 & 0.520 & -0.133 & -0.229 & 0.019 & -0.054 & -0.810 & -0.727 \\
C6 & 0.432 & -0.180 & -0.543 & 0.202 & 0.510 & 0.431 & -0.362 \\
\hline Eigenvalues & 0.215 & 0.881 & 0.115 & 0.381 & 0.131 & -0.038 & - \\
\hline
\end{tabular}

Note. Authors' elaboration.

\section{Appendix B Urban Districts with Gang Conflicts in Fortaleza}

In Fig. 4a, the urban districts of Fortaleza with large-scale gang conflicts in 2011 are: Barra do Ceará, Pirambu, Bom Jardim, Aerolândia, Jardim das Oliveiras, Messejana, and Jangurussu (see Castro, 2014). In Fig. 4b, urban districts with high-scale (red color) of gang conflicts are: Antônio Bezerra, Arraial Moura Brasil, Barra do Ceará, Bom Jardim, Edson Queiroz, Genbaú, Jacarecanga, José de Alencar, Messejana, Parque Dois Irmãos, Pici, Pirambu, Praia de Iracema, Sapiranga, and Vila Velha. While the urban districts with low-scale gang conflicts (orange color) are: Aerolândia, Barroso, Canindezinho, Conjunto Ceará I, Conjunto Ceará II, Conjunto 
Palmeiras, Granja Lisboa, Guajerú, Itaperi, Maraponga, Monte Castelo, Passaré, Praia do Futuro I, Praia do Futuro II, Siqueira, Serrinha, and Vincente Pinzon.

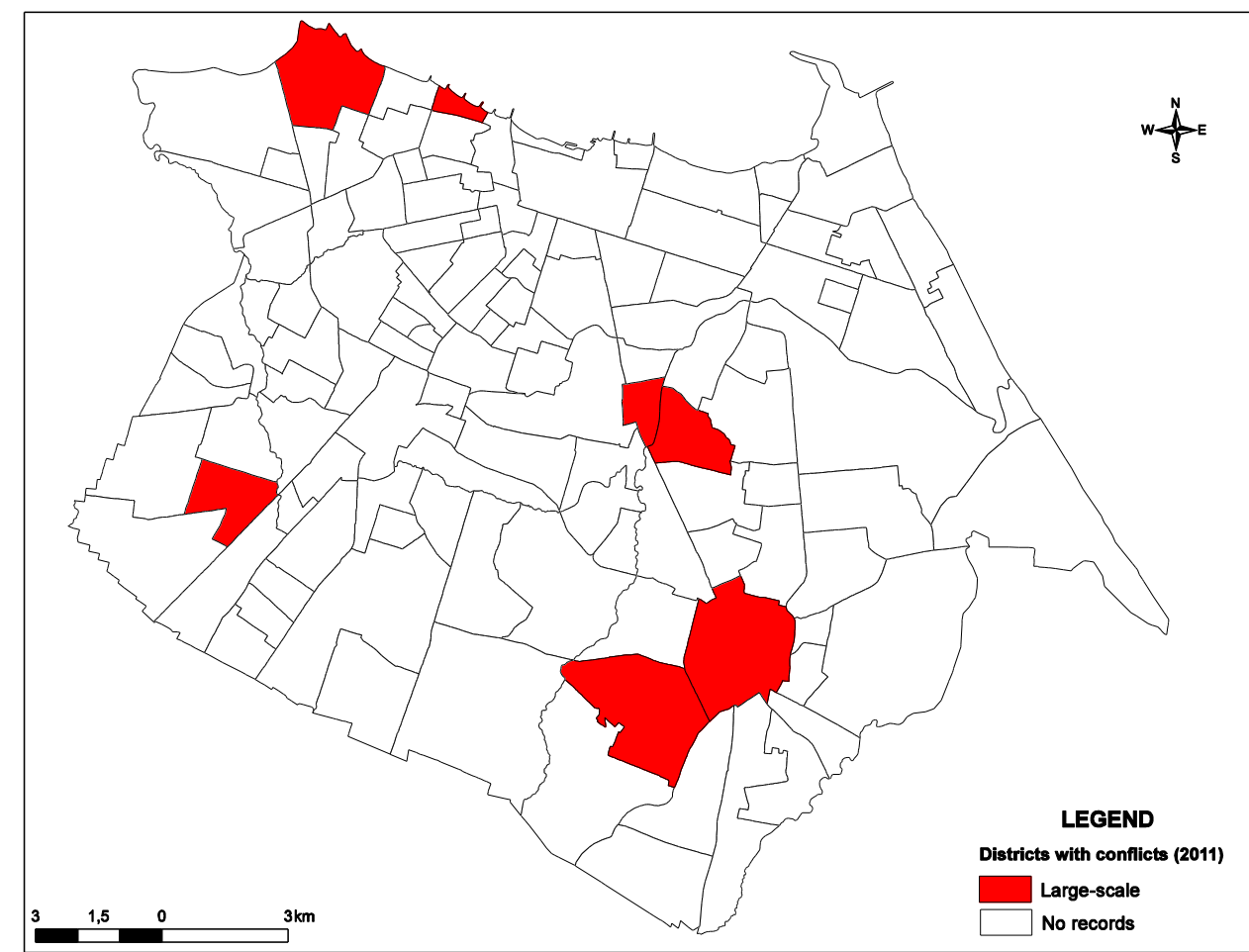

Fig. 4a: Urban Districts of Fortaleza with Gang Conflicts in 2011

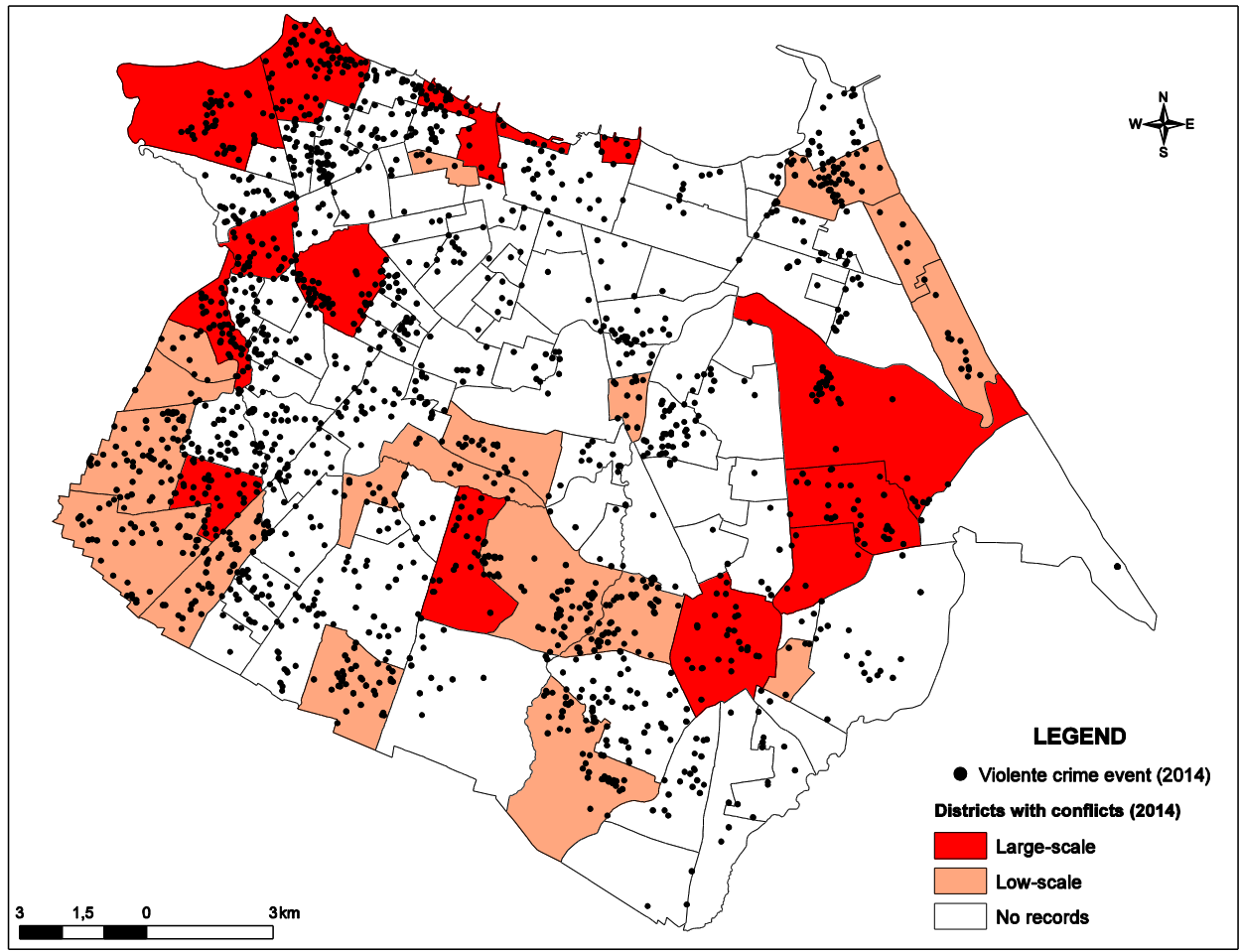

Fig. 4b: Urban Districts of Fortaleza with Gang Conflicts in 2014 


\section{References}

Alkimim, A., Clarke, K., \& Oliveira, F. (2013). Fear, crime, and space: The case of Viçosa, Brazil. Applied Geography, 42, 124-132.

Anselin, L. (1988). Spatial econometrics: methods and models. Kluwer Academic Publishers, Dordrecht, The Netherlands.

Bailey, W. (1984). Poverty, inequality, and city homicide rates. Criminology, 22(4), 531-550.

Becker, G. (1968). Crime and punishment: an economic approach. Journal of Political Economy, 76(2), 169217.

Blau, J., \& Blau, P. (1982). The cost of inequality: Metropolitan structure and violent crime. American Sociological Review, 47, 114-129.

Bourguignon, F. (1999). Crime, violence, and inequitable development. Annual World Bank Conference on Development Economics.

Carvalho, A., Cerqueira, D. \& Lobão, W. (2005). Socioeconomic structure, self-fulfilment, homicides and spatial dependence in Brazil. Texto para Discussão 1105, IPEA, Rio de Janeiro.

Carvalho, J. R., \& Lavor, S. (2009). Repeat property criminal victimization and income inequality in Brazil. Revista EconomiA, 9(4), 87-110.

Chiu, W. H., \& Madden, P. (1998). Burglary and income inequality. Journal of Public Economics, 69, $123-141$.

Cook, P. J. (1986). The demand and supply of criminal opportunities. Crime and Justice, 7, 1-27.

Corvalan, A., \& Vargas, M. (2015). Segregation and conflict: An empirical analysis. Journal of Development Economics, 116, 212-222.

Cutler, D. \& Glaeser, E. (1997). Are ghettos good or bad? The Quarterly Journal of Economics, 112(3), 827872 .

Da Silva, A. D. \& de Freitas, M. P. S. \& Pessoa, D. G. C. (2015). Assessing coverage of the 2010 Brazilian Census. Statistical Journal of the IAOS, 31, 215-225.

de Castro, B. (2014). Gangues impõem lei em 16 bairros. Jornal O Povo. Link: http://www.opovo.com.br/app/opovo/cotidiano/2014/02/10/noticiasjornalcotidiano,3204291/ganguesimpoem-lei-em-16-bairros.shtml

de Melo, S. , Matias, L. \& Andresen, M. (2015). Crime concentrations and similarities in spatial crime patterns in a Brazilian context. Applied Geography, 62, 314-324.

Ehrlich, I. (1973). Participation in illegitimate activities: A theoretical and empirical investigation. Journal of Political Economy, 81(3), 521-565.

Elhorst, J. P. (2014). Spatial econometrics: From cross-sectional data to spatial panels. Springer.

Fajnzylber, P., Lederman, D. \& Loayza, N. (2002a). What causes violent crime? European Economic Review, 46, 1323-1357.

Fanjzylber, P., Lederman, D. \& Loayza, N. (2002b): Inequality and violent crime. Journal of Low \& Economics, XLV, 1-40.

Faria, J., Ogura, L. \& Sachsida, A. (2013). Crime in a planned city: The case of Brasília. Cities, 32, 80-87.

FBSP (2015). Anuário brasileiro de segurança pública 2015. Fórum Brasileiro de Segurança Pública, São Paulo.

Freeman, R. (1999). The Economics of Crime. In: Handbook of Labor Economics, vol. 3, chap. 52, pp. 35293571. Elsevier B.V. 
Gaviria, A., \& Pagés, C. (2002). Patterns of crime victimization in Latin American cities. Journal of Development Economics, 67, 181-203.

Glaeser, E. \& Sacerdote, B. (1999). Why is there more crime in cities? Journal of Political Economy, 107(6), S225-S258.

Glebbeek, M.-L. \& Koonings, K. (2015). Between morro and asfalto. Violence, insecurity and socio-spatial segregation in Latin American cities. Habitat International, v54(1), 3-9.

Goldberg, M., Kim, K. \& Ariano, M. (2014). How firms cope with crime and violence. The World Bank, Washington DC.

Helsley, R., \& Strange, W. (1999). Gated communities and the economic geography of crime. Journal of Urban Economics, 46, 80-105.

Hicks, D., \& Hicks, J. (2014). Jealous of the joneses: Conspicuous consumption, inequality, and crime. Oxford Economic Papers, 66(4), 1090-1120.

IBGE (2011). Base de informações do censo demográfico 2010: Resultados do universo por setor censitário. Instituto Brasileiro de Geografia e Estatística, Rio de Janeiro.

Jacobs, J. (1961). The life and death of great American cities. Random House, New York.

Justus, M., Kahn, T. \& Kawamura, H. (2015). Relationship between income and repeat criminal victimization in Brazil. Revista EconomiA, 16(3), 295-309.

Kain, J. (1968). Housing segregation, negro employment and metropolitan decentralization. Quarterly Journal of Economics, LXXXI, 175-197.

Kang, S. (2015). Inequality and crime revisited: effects of local inequality and economic segregation on crime. Journal of Population Economics, 29(2), 593-626.

Kawachi, I., Kennedy, B. \& Wilkinson, R. (1999). Crime: Social disorganization and relative deprivation. Social Science \& Medicine, 48, 719-731.

Kelly, M. (2000). Inequality and crime. Review of Economics and Statistics, 82(4), 530-539.

Kennedy, B., Kawachi, I., Prothrow-Stith, D., Lochner, K. \& Gupta, V. (1998). Social capital, income inequality, and firearm violent crime. Social Science \& Medicine, 47(1), 7 - 17.

Krivo, L., \& Peterson, R. (1996). Extremely disadvantage neighborhood and urban crime. Social Forces, 75(2), 619-650.

LeSage, J., \& Pace, R. (2009). Introduction to spatial econometrics. CRC Press, United States.

Massey, D., \& Denton, N. (1988). The dimensions of residential segregation. Social Forces, 67(2), 281-315.

Massey, D., Rothwell, J. \& Domina, T. (2009). The changing bases of segregation in the United States. The ANNALS of the American Academy of Political and Social Science, 626, 74-90.

Menezes, T., Silveira-Neto, R., Monteiro, C. \& Ratton, J. (2013). Spatial correlation between homicide rates and inequality: Evidence from urban neighborhoods. Economic Letters, 120, 97-99.

Merton, R. (1968). Social theory and social structure. Free Press, New York.

Messner, S., Raffalovich, L. \& Shrock, P. (2002). Reassessing the cross-national relationship between income inequality and homicide rates: Implications of data quality control in the measurement of income distribution. Journal of Quantitative Criminology, 18(4), 377-395.

Mimmi, L., \& Ecer, S. (2010). An econometric study of illegal electricity connections in the urban favelas of Belo Horizonte, Brazil. Energy Policy, 38, 5081-5097. 
Murray, J., Cerqueira, D. \& Kahn, T. (2013). Crime and violence in Brazil: Systematic review of time trends, prevalence rates and risk factors. Aggression and Violent Behavior, 18(5), 471-483.

Pereira, D., Mota, C. \& Andresen, M. (2015). Social disorganization and homicide in Recife, Brazil. International Journal of Offender Therapy and Comparative Criminology, 1-23.

Quillian, L. (2012). Segregation and poverty concentration: the role of three segregations. American Sociological Review, 77(1), 354-379.

Sampson, R. J. (1986). The social ecology of crime. Chap. Neighbourhood Family Structure and the Risk of Personal Victimization, pp. 26-46. Springer-Verlag.

Sampson, R. \& Groves W. (1989). Community structure and crime: Testing social- disorganization theory. American Journal of Sociology, 94, 774-802.

Sen, A. (1999). Development as freedom. Oxford University Press, Oxford New York.

Skaperda, S., Soares, R., William, A. \& Miller, S. (2009). The costs of violence. The World Bank.

Soares, R. (2004). Development, crime and punishment: Accounting for the international differences in crime rates. Journal of Development Economics, 73, 155-184.

South, S. J., \& Messner, S. F. (2000). Crime and demography: Multiple linkages, reciprocal relations. Annual Review of Sociology, 26, 83-106.

Stigler, G. (1970). The Optimum Enforcement of Laws. Journal of Political Economy, 78(3), 526-536.

Taniguchi, T., Ratcliffe, J. \& Taylor, R. (2011). Gang set space, drug markets, and crime around drug corners in Camden. Journal of Research Crime \& Delinquency, 48(3), 327-363.

Tita, G., \& Cohen, J. (2004). Measuring spatial diffusion of shots fired activity across city neighborhoods. In: Spatially Integrated Social Science, 171-204. Oxford Press, New York.

Tita, G., Cohen, J. \& Engberg, J. (2005). An ecological study of the location of gang set space. Social Problems, (2), 272-299.

Tita, G., \& Radil, S. (2010). Making space for theory: the challenges of theorizing space and place for spatial analysis in criminology. Journal of Quantitative Criminology, 26, 467-479.

Tita, G., \& Radil, S. (2011). Spatializing the social networks of gangs to explore patterns of violence. Journal of Quantitative Criminology, (4), 521-545.

Tita, G. \& Ridgeway, G. (2007). The impact of gang formation on local patterns of crime. Journal of Research in Crime and Delinquency, (2), 208-237.

UNODC (2014). Global homicide statistics 2013. United Nations Publication, Vienna.

Wheeler, J. (2014). Violence and authority in Rio's favelas. Accord Series, 25, 95-99.

UNPD (2013) Regional human development report 2013-2014 - citizen security with a human face: Evidence and proposals for Latin America. Tech. rep., United Nations Development Programme.

WHO (2002). World report on violence and health. World Health Organization, Geneva.

Xie M (2010) The effects of multiple dimensions of residential segregation on black and Hispanic homicide victimization. Journal of Quantitative Criminology, 26:237-268. 